\title{
Relationship between work style and cigarette smoking in Japanese workers
}

\author{
Nobuyuki Miyatake $^{1^{\star}}$, Kenji Nishii ${ }^{2}$, Takeyuki Numata ${ }^{3}$ \\ ${ }^{1}$ Department of Hygiene, Faculty of Medicine, Kagawa University, Kagawa, Japan; \\ *Corresponding Author: miyarin@med.kagawa-u.ac.jp \\ ${ }^{2}$ Okayama Health Foundation Hospital, Okayama Health Foundation, Okayama, Japan; \\ ${ }^{3}$ Okayama Southern Institute of Health, Okayama Health Foundation, Okayama, Japan.
}

Received 30 June 2011; revised 1 August 2011; accepted 9 August 2011.

\begin{abstract}
We investigated the link between work style (i.e. day work and shift work) and cigarette smoking in Japanese workers. We used data of 3,238 men $(39.3 \pm 10.5$ years $)$ and 5,111 women $(37.1 \pm 10.9$ years), aged 20 - 59 years, by cross-sectional clinical investigation study. Work style i.e. day work and shift work, cigarette smoking, status of stress and stress coping were obtained by questionnaires by well-trained medical staff. A total of 227 men (7.0\%) and 339 women (6.6\%) were shift workers, and 1346 men (41.6\%) and 649 women (12.7\%) were current smokers. Work style was significantly linked to cigarette smoking, stress and stress coping after adjusting for age in women. In addition, the level of stress coping in subjects with cigarette smoking was significantly lower than that in subjects without cigarette smoking even after adjusting for age in women. However, these associations were not noted in men. Work style was critically associated with cigarette smoking in Japanese female workers.
\end{abstract}

Keywords: Work Style; Shift Work; Cigarette Smoking; Stress Coping

\section{INTRODUCTION}

Economic globalization needs continuous processing or operations around the clock to optimize manufacturing system. A 24-hour continuous operation system has become more popular and shift workers have become also more popular in Japan. Several reports have showed that shift work is associated with coronary artery disease [1], hyper cholesterolemia [2,3], weight gain [4] and hypertension [5].
Cigarette smoking is an important public health challenge, and it has been reported that $39.4 \%$ of men and $11.0 \%$ of women are current smokers in Japan [6]. Cigarette smoking is also a strong risk factor for atherosclerosis and cardiovascular disease in a dose-dependent manner [7]. However, the link between work style such as day work and shift work, and cigarette smoking in Japanese workers still remains to be investigated.

Therefore, in this study, we evaluated the link between work style and cigarette smoking and the effect of stress and stress coping on cigarette smoking in Japanese workers.

\section{SUBJECTS AND METHODS}

\subsection{Subjects}

We used data for 3238 Japanese male workers (39.3 \pm 10.5 years) and 5111 women (37.1 \pm 10.9 years), retrospectively from a database of 16,380 subjects who met the following criteria: 1) they had wanted to change their lifestyle i.e. diet and exercise habits, and had received an annual health check-up from June 1997 to Dec 2009 at Okayama Southern Institute of Health, 2) received evaluation of work style, cigarette smoking, status of stress and stress coping as part of the annual health check-up, 3) they were day workers and/or shift workers, aged 20 - 59 years, and 4) provided written informed consent (Table 1).

Ethical approval for the study was obtained from the Ethical Committee of Okayama Health Foundation.

\subsection{Work Style}

Subjects completed a self-administered questionnaire. This included the following question regarding patterns of work style: During your working life, until the present, what shift (time of day) did you work most: mainly day time, mainly night (i.e. fixed-night shift), or alternate 
Table 1. Clinical profiles of enrolled subjects.

\begin{tabular}{lcc}
\hline & Men & Women \\
\hline Number of subjects & 3238 & 5111 \\
Age & $39.3 \pm 10.5$ & $37.1 \pm 10.9$ \\
Height $(\mathrm{cm})$ & $167.0 \pm 5.8$ & $157.2 \pm 5.4$ \\
Body weight $(\mathrm{kg})$ & $71.2 \pm 11.7$ & $54.8 \pm 9.2$ \\
Body mass index $\left(\mathrm{kg} / \mathrm{m}^{2}\right)$ & $24.6 \pm 3.7$ & $22.2 \pm 3.6$ \\
Abdominal circumference $(\mathrm{cm})$ & $83.9 \pm 10.2$ & $70.3 \pm 9.2$ \\
Hip circumference $(\mathrm{cm})$ & $94.6 \pm 6.2$ & $91.0 \pm 6.1$ \\
& & Mean $\pm \mathrm{SD}$ \\
\hline
\end{tabular}

night and daytime (that is, rotating-shift work)? In this study, we excluded 65 male and 131 female night workers to evaluate the influence of shift work on cigarette smoking compare to day workers.

\subsection{Exposure Data}

The self-administered questionnaire also inquired about other characteristics of smoking status (never or current smoker), status of stress (yes or no) and stress coping (yes or no).

\subsection{Anthropometric Measurements}

The anthropometric parameters were evaluated by using the following respective parameters such as height, body weight, body mass index (BMI), abdominal circumference, hip circumference. BMI was calculated by weight/[height $]^{2}\left(\mathrm{~kg} / \mathrm{m}^{2}\right)$. The abdominal circumference was measured at the umbilical level and the hip was measured at the widest circumference over the trochanter in standing subjects after normal expiration [8].

\subsection{Statistical Analysis}

Data are expressed as mean \pm standard deviation (SD) values. A comparison of parameters was performed by $\chi^{2}$ test and logistic regression analysis: $p<0.05$ was considered to be statistically significant. Statistical analysis was performed with StatView 5.0 (SAS Institute Inc., Cary, NC, USA).

\section{RESULTS}

A total of 227 men (7.0\%) and 339 women (6.6\%) were shift workers, and the rate of shift workers was the highest in 20's in both sexes (Table 2).

Table 3 shows the comparison of cigarette smoking as classified by age group. Current smokers were decreased with age in both sexes, and 1346 men (41.6\%) and 649 women (12.7\%) were current smokers.

We also evaluated the status of stress (Table 4). 2071 men $(64.0 \%)$ and 3,735 women $(73.1 \%)$ women answered as having stress, and the rate of subjects with having stress was the highest in 30's in both sexes. However, subjects with having stress coping was comparably lower [1539 men (47.5\%) and 2730 women (53.5\%)] (Table 5). The rate of subjects with having stress coping was the highest in 20's in men and in 50's in women.

In addition, we evaluated the relationship between work style and cigarette smoking, status of stress and stress coping. In women, the rate of current smoker and having stress was significantly higher in shift workers than those in day workers after adjusting for age (Table 6). The rate of having stress coping in shift workers was significantly higher than that in day workers after adjusting for age. In men, those clear associations were not noted.

Finally, we investigated the relationship between cigarette smoking and status of stress and stress coping (Table 7). The rate of having stress coping in current smokers was significantly lower than that in non smokers even after adjusting for age in women, but not in men. The relationship between cigarette smoking and status of stress was not noted in both sexes.

\section{DISCUSSION}

We evaluated the link between work style and cigarette smoking in Japanese workers and we found that close associations between shift work and cigarette smoking in female workers. In addition, having stress coping might be important for Japanese female workers for prohibiting smoking.

In some literatures, work style was closely associated with cigarette smoking especially male workers. Fujino et al. reported that the rate of current smoker was higher in shift male workers $(59.5 \%)$ than that in day male workers (55.4\%) in Japan Collaborative Cohort Study for the Evaluation of Cancer Risk (JACC Study) [1]. Dochi et al. also reported that the rate of current smoker was higher in shift workers (68.8\%) than that in day workers (58.8\%) in male workers in steel company [2]. Suwazono et al. also showed that shift work was closely associated with cigarette smoking in male workers [4]. There were few studies that evaluated the relationship between shift work and cigarette smoking in Japanese female workers. Kageyama et al. reported that the prevalenve of current smoker was $29 \%$, being higher than that in the general population of Japanese women by evaluating 522 Japanese female staff nurses [9]. In this study, it is note worthy that we found the relationship between work style and cigarette smoking in women 
even after adjusting for age. However, those associations were not noted as previous study in men. Enrolled subjects in this study were undertaken health check-up and they wanted to change their lifestyle. Therefore close associations might not be noted in men.

According to the relation between work style and status of stress, 3-shift system of employment increases workrelated stress [10]. Parkes carried out cross-sectional

Table 2. Comparison of work style as classified by age group.

\begin{tabular}{ccccccccc}
\hline & \multicolumn{3}{c}{ Men } & \multicolumn{5}{c}{ Women } \\
\cline { 2 - 9 } & Day work & $\%$ & Shift work & $\%$ & Day work & $\%$ & Shift work & $\%$ \\
\hline $20-29$ & 661 & 90.4 & 70 & 9.6 & 1575 & 90.0 & 175 & 10.0 \\
$30-29$ & 888 & 92.6 & 71 & 7.5 & 1135 & 93.5 & 79 & 6.5 \\
$40-49$ & 790 & 93.7 & 53 & 6.3 & 1207 & 95.3 & 59 & 4.7 \\
$50-59$ & 672 & 95.3 & 33 & 4.7 & 855 & 97.0 & 26 & 3.0 \\
Total & 3011 & 93.0 & 227 & 7.0 & 4772 & 93.4 & 339 & 6.6 \\
\hline
\end{tabular}

Table 3. Comparison of cigarette smoking as classified by age group.

\begin{tabular}{ccccccccc}
\hline & \multicolumn{4}{c}{ Men } & \multicolumn{4}{c}{ Women } \\
\cline { 2 - 8 } & Cigarette smoking $(+)$ & $\%$ & Cigarette smoking $(-)$ & $\%$ & Cigarette smoking $(+)$ & $\%$ & Cigarette smoking $(-)$ & $\%$ \\
\hline $20-29$ & 329 & 45.0 & 402 & 55.0 & 281 & 16.1 & 1469 & 83.9 \\
$30-29$ & 413 & 43.1 & 546 & 56.9 & 179 & 14.7 & 1035 & 85.3 \\
$40-49$ & 349 & 41.4 & 494 & 58.6 & 130 & 10.3 & 1136 & 89.7 \\
$50-59$ & 255 & 36.2 & 450 & 63.8 & 59 & 6.7 & 822 & 93.3 \\
Total & 1346 & 41.6 & 1892 & 58.4 & 649 & 12.7 & 4462 & 87.3 \\
\hline
\end{tabular}

Table 4. Comparison of stress as classified by age group.

\begin{tabular}{ccccccccc}
\hline & \multicolumn{3}{c}{ Men } & \multicolumn{5}{c}{ Women } \\
\cline { 2 - 8 } & Stress (+) & $\%$ & Stress (-) & $\%$ & Stress (+) & $\%$ & Stress $(-)$ & $\%$ \\
\hline $20-29$ & 443 & 60.6 & 288 & 39.4 & 1297 & 74.1 & 453 & 25.9 \\
$30-29$ & 645 & 67.3 & 314 & 32.7 & 925 & 76.2 & 289 & 23.8 \\
$40-49$ & 566 & 67.1 & 277 & 32.9 & 910 & 71.9 & 356 & 28.1 \\
$50-59$ & 417 & 59.1 & 288 & 40.9 & 603 & 68.4 & 278 & 31.6 \\
Total & 2071 & 64.0 & 1167 & 36.0 & 3735 & 73.1 & 1376 & 26.9 \\
\hline
\end{tabular}

Table 5. Comparison of stress coping as classified by age group.

\begin{tabular}{ccccccccc}
\hline & \multicolumn{3}{c}{ Men } & \multicolumn{4}{c}{ Women } \\
\cline { 2 - 8 } & Stress coping $(+)$ & $\%$ & Stress coping $(-)$ & $\%$ & Stress coping $(+)$ & $\%$ & Stress coping $(-)$ & $\%$ \\
\hline $20-29$ & 377 & 51.6 & 354 & 48.4 & 957 & 54.7 & 793 & 45.3 \\
$30-29$ & 419 & 43.7 & 540 & 56.3 & 642 & 52.9 & 572 & 47.1 \\
$40-49$ & 405 & 48.0 & 438 & 52.0 & 631 & 49.8 & 635 & 50.2 \\
$50-59$ & 338 & 47.9 & 367 & 52.1 & 500 & 56.8 & 381 & 43.1 \\
Total & 1539 & 47.5 & 1699 & 52.5 & 2730 & 53.4 & 2381 & 46.6 \\
\hline
\end{tabular}


Table 6. Relationship between work style and cigarette smoking, stress and stress coping.

\begin{tabular}{|c|c|c|c|c|}
\hline Men & Cigarette smoking $(+)$ & Cigarette smoking (-) & $p$ & $p$ (After adjusting for age) \\
\hline Day work & 1248 & 1763 & \multirow[b]{2}{*}{0.6113} & \multirow[b]{2}{*}{0.7664} \\
\hline \multirow[t]{2}{*}{ Shift work } & 98 & 129 & & \\
\hline & Stress $(+)$ & Stress $(-)$ & \multirow{4}{*}{0.7950} & \multirow{4}{*}{0.8360} \\
\hline Day work & 1924 & 1087 & & \\
\hline \multirow[t]{2}{*}{ Shift work } & 147 & 80 & & \\
\hline & Stress coping $(+)$ & Stress coping (-) & & \\
\hline Day work & 1419 & 1592 & \multirow[b]{2}{*}{0.0951} & \multirow[b]{2}{*}{0.1054} \\
\hline Shift work & 120 & 107 & & \\
\hline Women & Cigarette smoking $(+)$ & Cigarette smoking (-) & & \\
\hline Day work & 574 & 4198 & \multirow{2}{*}{$<0.0001$} & \multirow{2}{*}{$<0.0001$} \\
\hline \multirow[t]{2}{*}{ Shift work } & 75 & 264 & & \\
\hline & Stress $(+)$ & Stress $(-)$ & \multirow{4}{*}{$<0.0001$} & \multirow{4}{*}{$<0.0001$} \\
\hline Day work & 3444 & 1328 & & \\
\hline \multirow[t]{2}{*}{ Shift work } & 291 & 48 & & \\
\hline & Stress coping $(+)$ & Stress coping (-) & & \\
\hline Day work & 2505 & 2267 & \multirow[b]{2}{*}{$<0.0001$} & \multirow[b]{2}{*}{$<0.0001$} \\
\hline Shift work & 225 & 114 & & \\
\hline
\end{tabular}

Table 7. Relationship between cigarette smoking and stress, stress coping.

\begin{tabular}{|c|c|c|c|c|}
\hline Men & Stress $(+)$ & Stress (-) & $p$ & $p$ (After adjusting for age) \\
\hline Cigarette smoking $(+)$ & 840 & 506 & \multirow{2}{*}{0.1208} & \multirow{2}{*}{0.1053} \\
\hline \multirow[t]{2}{*}{ Cigarette smoking (-) } & 1231 & 661 & & \\
\hline & Stress coping $(+)$ & Stress coping (-) & & \\
\hline Cigarette smoking (+) & 602 & 744 & \multirow[b]{2}{*}{0.0070} & \multirow[b]{2}{*}{0.1054} \\
\hline Cigarette smoking (-) & 937 & 955 & & \\
\hline Women & Stress $(+)$ & Stress $(-)$ & & \\
\hline Cigarette smoking (+) & 496 & 153 & \multirow{3}{*}{0.0396} & \multirow{3}{*}{0.0797} \\
\hline \multirow[t]{2}{*}{ Cigarette smoking (-) } & 3239 & 1223 & & \\
\hline & Stress coping $(+)$ & Stress coping (-) & & \\
\hline Cigarette smoking (+) & 321 & 328 & \multirow[b]{2}{*}{0.0307} & \multirow[b]{2}{*}{$<0.0001$} \\
\hline Cigarette smoking (-) & 2409 & 2053 & & \\
\hline
\end{tabular}

research targeting 736 two-shift workers and 1131 day workers at an oil refinery, and concluded that the 2-shift workers had higher job demand and less job control over their work [11]. In female workers, Kageyama et al. reported that the cigarette smoking-dependent tendency was associated with recent life events and the presence of insomnia [9]. Stress is probably the most important contributor to excess smoking levels [12]. American study showed that officers who smoked experienced high-stress levels more than twice that of non smokers [13]. Therefore, stress coping may important for prohibiting cigarette smoking. Serxner et al. recommended that 
smoking cessation and prevention programs should focus on change in individual coping mechanisms [14]. We also found that the rate of stress in shift smokers was higher than that in day workers and the rate of stress coping was also higher in shift workers than that in day workers after adjusting in women. Although the rate of stress coping was higher in shift workers than that in day workers, the rate of stress coping was significantly lower than in current smokers than that in non smokers in women. Taken together, it seems reasonable to suggest that simply recommending proper stress coping except cigarette smoking, might result in decreased cigarette smoking in some Japanese female workers.

Potential limitations remain in this study. First, our study was a cross sectional and not a longitudinal study. Second, the 3238 Japanese male workers and 5111 women, all of whom wanted to change their lifestyle, underwent measurements for this study: they were therefore more health-conscious than the average person. In fact, in men, clear associations were not noted the relationship between shift work and cigarette smoking as previous studies $[1,2,4]$. Third, we could not obtain the data of the average number of cigarettes smoked per day or subject' age when they started smoking. Subjects who smoked before the date of the analysis but who had stopped by then would have therefore been categorized as non-smokers. Fourth, status of stress and stress coping was evaluated by simple questionnaire (yes or no). Therefore, further prospective studies are needed in Japanese workers to prove the link between work style and cigarette smoking.

\section{CONFLICT OF INTEREST}

There is no conflict of interest.

\section{REFERENCES}

[1] Fujino, Y., Iso, H., Tamakoshi, A., Ishiba, Y., Koizumi, A., Kubo, T. and Yoshimura, T. (2006) Japanese Collaborative Cohort Study Group: A prospective cohort study of shift work and risk of ischemic heart disease in Japanese male workers. American Journal of Epidemiology, 164, 128-135. doi:10.1093/aje/kwj185

[2] Dochi, M., Sakata, K., Oishi, M., Tanaka, K., Kobayashi, E. and Suwazono, Y. (2008) Relationship between shif work and hyper cholesterolemia in Japan. Scandinavian Journal of Work, Environment \& Health, 34, 33-39.

[3] Dochi, M., Suwazono, Y., Sakata, K., Okubo, Y., Oishi, M., Tanaka, K., Kobayashi, E. and Nogawa, K. (2009) Shift work is a risk factor for increased total cholesterol level: A 14-year prospective cohort study in 6886 male workers. Occupational and Environmental Medicine, 66, 592-597. doi:10.1136/oem.2008.042176

[4] Suwazono, Y., Dochi, M., Sakata, K., Okubo, Y., Oishi, M., Tanaka, K., Kobayashi, E., Kido, T. and Nogawa, K. (2008) A longitudinal study on the effect of shift work on weight gain in male Japanese workers. Obesity (Silver Spring), 16, 1887-1893. doi:10.1038/oby.2008.298

[5] Suwazono, Y., Dochi, M., Sakata, K., Okubo, Y., Oishi, M., Tanaka, K., Kobayashi, E. and Nogawa, K. (2008) Shift work is a risk factor for increased blood pressure in Japanese men: A 14-year historical cohort study. Hypertension, 52, 581-586.

doi:10.1161/HYPERTENSIONAHA.108.114553

[6] The National Nutrition Survey in Japan (2010). http://www.mhlw.go.jp/houdou/2008/12/dl/h1225-5j.pdf

[7] Peto, R. (1994) Smoking and death: The past 40 years and the next 40. British Medical Journal, 209, 937-939.

[8] Anonym (2005) Definition and the diagnostic standard for metabolic syndrome-Committee to Evaluate Diagnostic Standards for Metabolic Syndrome. Nippon Naika Gakkai Zasshi, 94, 794-809. doi:10.2169/naika.94.794

[9] Kageyama, T., Kobayashi, T., Nishikido, N., Oga, J. and Kawashima, M. (2005) Associations of sleep problems and recent life events with smoking behaviors among female staff nurses in Japanese hospitals. Industrial Health, 43, 133-141. doi:10.2486/indhealth.43.133

[10] Harada, H., Suwazono, Y., Sakata, K., Okubo, Y., Oishi, M., Uetani, M., Kobayashi, E. and Nogawa, K. (2005) Three-shift system increases job-related stress in Japanese workers. Journal of Occupational Health, 47, 397-404. doi:10.1539/joh.47.397

[11] Parkes, K.R. (2003) Shift work and environment as interactive predictors of work perceptions. Journal of Occupational Health Psychology, 8, 266-281. doi:10.1037/1076-8998.8.4.266

[12] Smith, D.R., Devine, S., Leggat, P.A. and Ishitake, T. (2005) Alcohol and tobacco consumption among police officers. Kurume Medical Journal, 52, 63-65. doi:10.2739/kurumemedj.52.63

[13] Kohan, A. and O’Connor, B.P. (2002) Police officer job satisfaction in relation to mood, well-being, and alcohol consumption. The Journal of Psychology, 136, 307-318.

[14] Serxner, S., Catalano, R., Dooley, D. and Mishra, S. (1991) Tobacco use: Selection, stress, or culture? Journal of Occupational Medicine, 33, 1035-1039. 